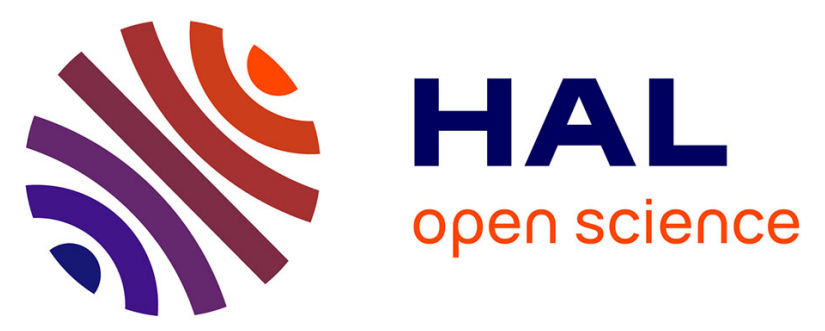

\title{
Betaproteobacteria dominance and diversity shifts in the bacterial community of a PAH-contaminated soil exposed to phenanthrene.
}

Florence Martin, Stéphane Torelli, Denis Le Paslier, Agnès Barbance, Fabrice Martin-Laurent, David Bru, Roberto Geremia, Gérard Blake, Yves Jouanneau

\section{To cite this version:}

Florence Martin, Stéphane Torelli, Denis Le Paslier, Agnès Barbance, Fabrice Martin-Laurent, et al.. Betaproteobacteria dominance and diversity shifts in the bacterial community of a PAHcontaminated soil exposed to phenanthrene.. Environmental Pollution, 2012, 162, pp.345-53. 10.1016/j.envpol.2011.11.032 . hal-01063697

\section{HAL Id: hal-01063697 https://hal.science/hal-01063697}

Submitted on 15 Sep 2014

HAL is a multi-disciplinary open access archive for the deposit and dissemination of scientific research documents, whether they are published or not. The documents may come from teaching and research institutions in France or abroad, or from public or private research centers.
L'archive ouverte pluridisciplinaire HAL, est destinée au dépôt et à la diffusion de documents scientifiques de niveau recherche, publiés ou non, émanant des établissements d'enseignement et de recherche français ou étrangers, des laboratoires publics ou privés. 


\section{Betaproteobacteria dominance and diversity shifts in the bacterial community of a}

2 PAH-contaminated soil exposed to phenanthrene

3 Florence Martin ${ }^{\mathrm{a}, \mathrm{b}}$, Stéphane Torelli ${ }^{\mathrm{a}, \mathrm{b}}$, Denis Le Paslier ${ }^{\mathrm{c}, \mathrm{d}, \mathrm{e}}$, Agnès Barbance ${ }^{\mathrm{c}, \mathrm{d}, \mathrm{e}}$, Fabrice

4 Martin-Laurent $^{\mathrm{f}}$, David Bru ${ }^{\mathrm{f}}$, Roberto Geremia ${ }^{\mathrm{g}}$, Gérard Blake ${ }^{\mathrm{h}}$ and Yves Jouanneau, ${ }^{\mathrm{a}, \mathrm{b}^{*}}$

5

$6 \quad{ }^{a}$ CEA, DSV, iRTSV, Laboratoire de Chimie et Biologie des Métaux, F-38054 Grenoble.

$7 \quad{ }^{\mathrm{b}} \mathrm{UJF}-G r e n o b l e ~ 1 / C N R S$, UMR 5249, F-38041, Grenoble, France

$9{ }^{\mathrm{c}}$ CEA, DSV, Institut de Génomique, Genoscope, 2 rue Gaston Crémieux, F-91057 Evry.

$10 \quad{ }^{\mathrm{d}}$ CNRS-UMR 8030 F-91057 Evry.

$11{ }^{\mathrm{e}}$ UEVE, Université d'Evry, F-91057 Evry, France

12

13 fINRA, Université de Bourgogne, UMR 1229 Microbiologie du Sol et de l'Environnement, 14 BP 86510, 21065 Dijon Cedex, France

15

${ }^{\mathrm{g}}$ UJF-Grenoble 1/CNRS, UMR 5553 Laboratoire d'Ecologie Alpine, F-38041 Grenoble,

17 France

18

${ }^{\text {h}}$ LOCIE, Université de Savoie, F-73376 Le Bourget-du-Lac, France

20

$21{ }^{*}$ Corresponding author: Yves Jouanneau, LCBM/iRTSV, CEA-Grenoble, F-38054 Grenoble

22 Cedex 9, France. Tel. : 334387843 10; Fax : 33438785487

23

yves.jouanneau@cea.fr 


\section{Abstract}

26 In this study, the PAH-degrading bacteria of a constructed wetland collecting road runoff has 27 been studied through DNA stable isotope probing. Microcosms were spiked with ${ }^{13} \mathrm{C}$ 28 phenanthrene at 34 or 337 ppm, and bacterial diversity was monitored over a 14-day period.

29 At 337 ppm, PAH degraders became dominated after 5 days by Betaproteobacteria, including 30 novel Acidovorax, Rhodoferax and Hydrogenophaga members, and unknown bacteria related

31 to Rhodocyclaceae. The prevalence of Betaproteobacteria was further demonstrated by 32 phylum-specific quantitative PCR, and was correlated with a burst of phenanthrene 33 mineralization. Striking shifts in the population of degraders were observed after most of the 34 phenanthrene had been removed. Soil exposed to $34 \mathrm{ppm}$ phenanthrene showed a similar 35 population of degraders, albeit only after 14 days. Our results indicate that specific 36 Betaproteobacteria are involved in the main response to soil PAH contamination, and 37 illustrate the potential of SIP approaches to identify soil PAH degraders.

38 Key words : 16S rRNA sequences; stable isotope probing; PAH degradation; phenanthrene; 39 Betaproteobacteria

42 Capsule : On a site collecting road runoff, implementation of stable isotope probing to 43 identify soil bacteria responsible for phenanthrene degradation, led to the discovery of new 44 Betaproteobacteria distantly related to known PAH degraders. 
47 Among the environmental pollutants that perturb ecosystems and threaten human beings, polycyclic aromatic hydrocarbons (PAHs) are of special concern because they are persistent and accumulate along the trophic chain. To clean up contaminated sites, bioremediation strategies have been proposed based on the ability of particular microorganisms to degrade PAHs (Doyleet al., 2008). Numerous bacterial isolates able to utilize PAHs as carbon sources have been described, and the biochemical pathways responsible for their oxidative degradation have been investigated (Penget al., 2008). Based on their frequent occurrence on polluted sites and their metabolic potential, members of the Sphingomonadaceae and Actinobacteria are considered potent PAH degraders in soil or sediments (Leyset al., 2004; Leyset al., 2005; Alonso-Gutierrezet al., 2009). However, in the last decade, cultureindependent studies highlighted the great bacterial diversity in environmental ecosystems such as soils, and showed that culturable bacteria represented less than $5 \%$ of the existing species (Coleet al., 2010). Hence, PAH-degrading strains described so far might not be representative of soil bacteria that actually remove pollutants in situ. Consistent with this idea, investigations involving a selective labeling of the bacteria of interest through stable-isotope probing (SIP (Radajewskiet al., 2000)) led to the discovery of new bacteria involved in pollutant degradation (Wackett, 2004). SIP-based methods permit the exploration of uncultured bacteria present in natural or contaminated environments and reduce biases associated with selection in artificial media (Dumont and Murrell, 2005). Using a field-based SIP strategy to track naphthalene degraders on a coal tar contaminated site, Jeon et al.

67 identified a novel Polaromonas strain, as the major players (Jeonet al., 2003). In studies 68 targeting naphthalene-, phenanthrene- or pyrene-degrading bacteria in a bioreactor treating PAH-contaminated soil, different bacterial taxa were detected depending on the PAHsubstrate used as probe (Singletonet al., 2005; Singletonet al., 2006). An Acidovorax strain, 
71 which was found to be dominant among phenanthrene-degrading bacteria, was later isolated 72 and characterized as a novel PAH degrader (Singletonet al., 2009). Recently, bacteria related 73 to the Pseudoxanthomonas and Microbacterium genera were identified as the main 74 phenanthrene degraders in soil but diversity changes were observed in soil also treated with 75 root exudates (Cebronet al., 2011). In another SIP-based study targeting anthracene-degrading 76 bacteria, dominant soil degraders were found to be affiliated to the Sphingomonadales and 77 Variovorax taxa (Joneset al., 2011).

78 In the present study, we have implemented a SIP strategy to explore the diversity of a PAH79 degrading community in a constructed wetland collecting the road runoff from a highway. 80 Using ${ }^{13} \mathrm{C}$-phenanthrene as tracer, we examined changes in the soil $\mathrm{PAH}$-degrader population 81 as a function of the dose and time of exposure to the tracer. For this purpose, soil DNA was 82 extracted after various SIP treatments, separated by isopycnic centrifugation, and labeled 83 DNA were used to identify phenanthrene degraders based on 16S rRNA gene sequences. . 84 Moreover, dose- and time-dependent changes in the composition of the phenanthrene-exposed 85 bacterial community were monitored by a combination of molecular methods, including 86 single-strand conformation polymorphism and quantitative PCR. Results revealed that, in 87 addition to Burkholderiales, bacteria related to the Rhodocyclaceae and Thiobacillus taxa 88 appeared as new potential phenanthrene degraders. Our data also provide new insights into 89 the response of a large panel of specific degraders, mostly undescribed, to soil PAH 90 contamination. 


\section{MATERIALS AND METHODS}

\section{Sampling site and determination of soil PAH concentration}

Soil samples were obtained from a constructed wetland collecting road runoffs from a highway near Chambéry (France) in October 2008. The facility, administered by the AREA company, was colonized by Typha latifolia and Phragmites australis all over the structure. Soil was sampled from the 10-cm upper layer, sieved to about $3 \mathrm{~mm}$ and stored in a closed plastic box at $4^{\circ} \mathrm{C}$ until use. The physico-chemical composition of the soil used will be given elsewhere.

\section{Synthesis of $\left[\mathrm{U}-^{13} \mathrm{C}\right]-$ phenanthrene}

$\left[\mathrm{U}-{ }^{13} \mathrm{C}\right]$-phenanthrene was prepared from $\left[\mathrm{U}-{ }^{13} \mathrm{C}\right]$ succinic anhydride and $\left[\mathrm{U}-{ }^{13} \mathrm{C}\right]$ naphthalene (both from Sigma-Aldrich), according to a previously described method (Singleton, et al., 2005) and references cited therein) with minor modifications. The product was obtained in five steps with a yield of approximately $44 \%$. The purity and homogeneity of the final preparation were checked by ${ }^{1} \mathrm{H}$ NMR in $\mathrm{CDCl}_{3}$ (Fig. S1) and GC-MS (m/z $=192$ $\left.\left(\mathrm{M}^{+}\right)\right)$. A detailed description of the preparation procedure is available upon request.

\section{Microcosm setup and incubation conditions}

Incubations were performed in $250 \mathrm{ml}$ sterilized glass Erlenmeyer flasks, closed with rubber stoppers. Microcosms consisted of $20 \mathrm{~g}$ wet soil (water content, $59 \%$, vol/wt) and $5 \mathrm{ml}$ of a salt solution $\left(7.5 \mathrm{mM}\left(\mathrm{NH}_{4}\right)_{2} \mathrm{SO}_{4}-20 \mathrm{mM} \mathrm{KH}_{2} \mathrm{PO}_{4}-30.6 \mathrm{mM} \mathrm{Na}_{2} \mathrm{HPO}_{4}-0.18 \mathrm{mM} \mathrm{CaCl}_{2}-\right.$ 3.6 $10^{-2} \mathrm{mM} \mathrm{FeSO}_{4}-0.81 \mathrm{mM} \mathrm{MgSO}_{4}$ ), added to favor bacterial metabolism. [U- $\left.{ }^{13} \mathrm{C}\right]-$ phenanthrene was supplied as a $54.9 \mathrm{mM}$ stock solution in dimethylsulfoxide (DMSO) to give final concentrations of either 33.7 or 337 ppm (on a dry wt basis), equivalent to levels 200- or 
117 2000-fold as high as that of phenanthrene initially found in soil. Relevant microcosm

118 experiments were referred to as SIP200 and SIP2000, respectively. Two microcosms supplied

119 with 337 ppm labeled phenanthrene were inoculated with approx. $210^{8}$ cells $(0.2 \mathrm{ml})$ of a

120 washed culture of Sphingomonas CHY-1 (Willison, 2004). Three types of control flasks were

121 also prepared, which contained either unlabeled phenanthrene (added at $34 \mathrm{ppm}$ as for

122 SIP200), no additional carbon source, or sodium azide $\left(7.710^{-5} \mathrm{~mol} / \mathrm{g}\right.$ dry soil; abiotic

123 control). Microcosms containing [U- ${ }^{13}$ C]-phenanthrene (SIP200 and SIP2000) were prepared

124 in 9 replicates (triplicates at 3 time points), whereas controls with unlabelled phenanthrene or

125 microcosms inoculated with strain CHY-1 were performed in 6 replicates (duplicates at 3

126 time points). Other control flasks were incubated in duplicates. Flasks were incubated at $25^{\circ} \mathrm{C}$

127 in static mode in a dark room.

128

129 PAH extraction from soil and quantification

130 Soil samples (1g) were mixed with $1 \mathrm{~g}$ anhydrous sodium sulfate and $10 \mathrm{~mL}$ hexane in $30-\mathrm{mL}$

131 glass tubes closed with Teflon-sealed screw-caps. Suspensions were homogenized by Vortex

132 mixing and treatment in an ultrasonic bath for a total time of $1 \mathrm{~h}$. Soil samples were extracted

133 once more with hexane and organic phases were combined, centrifuged for $12 \mathrm{~min}$ at $7400 \mathrm{~g}$

134 before evaporation to dryness under argon. Dry extracts were dissolved in $0.5 \mathrm{ml}$ acetonitrile.

135 Residual ${ }^{13} \mathrm{C}$-phenanthrene was extracted in the same way.

136 Quantification of the 16 priority PAHs was performed with a HP6890 gas chromatograph

137 coupled to a HP5973 mass spectrometer (Agilent Technologies). PAHs were separated on a

138 MDN12 column (30 m by $0.25 \mathrm{~mm}, 25 \mu \mathrm{m}$ film thickness; Supelco) as previously described

139 (Krivoboket al., 2003). The mass detector was operated in the single-ion monitoring mode.

140 PAHs were eluted between 8.9 and $32.7 \mathrm{~min}$. Concentrations were determined using

141 calibration curves obtained from dilutions of a standard mixture of the 16 PAHs $(0.1 \mathrm{mg} / \mathrm{ml}$, 
142 Agilent Technologies). ${ }^{13} \mathrm{C}$-phenanthrene was quantified from the area of the peak detected at $143 \mathrm{~m} / \mathrm{z}: 192$ using unlabelled phenanthrene as a standard.

145 Monitoring of mineralization by GC/MS analysis

146 Quantification of $\mathrm{CO}_{2}$ evolved in the headspace of microcosms was performed by GC/MS 147 analysis on $25 \mu 1$ samples of the gas phase withdrawn with a gastight syringe. Analysis was 148 carried out on the same apparatus as above equipped with an HP-PLOT/Q column (15 m by $1490.32 \mathrm{~mm}, 20 \mu \mathrm{m}$ film thickness; Agilent Technologies) with helium as carrier gas maintained 150 at a flow rate of $36 \mathrm{ml} / \mathrm{min}$. The $\mathrm{GC}$ was run in the isothermal mode at $40^{\circ} \mathrm{C}$ with a split ratio

151 of $12: 1 .{ }^{13} \mathrm{CO}_{2}(\mathrm{~m} / \mathrm{z}=45)$ or ${ }^{12} \mathrm{CO}_{2}(\mathrm{~m} / \mathrm{z}=44)$ were measured with the MS operated in the 152 single-ion monitoring mode. Concentrations were determined from peak area using a 153 calibration curve in the 0 to $200 \mu \mathrm{M}$ range made with known mixtures of $\mathrm{CO}_{2}$ in argon. Net

$154{ }^{13} \mathrm{CO}_{2}$ produced in microcosm headspaces was calculated by subtracting background ${ }^{13} \mathrm{CO}_{2}$ 155 present in the air.

157 SSCP fingerprint analyses of 16S rRNA genes

158 For each tested experimental condition, $1 \mathrm{~g}$ of soil (wet weight) was sampled and divided into 159 three 250-mg soil aliquots, thus making 3 replicates per flask. DNA was extracted using the 160 Power Soil extraction kit (MO BIO Laboratories). DNA samples were adjusted to $10 \mathrm{ng} / \mu 1$ 161 and used as templates to amplify the V3 region of the 16S rRNA genes. PCR conditions and 162 subsequent capillary electrophoresis were performed as previously described (Zingeret al., 163 2007). SSCP profiles were computed and normalized. Nonmetric multidimensional scaling 164 (NMDS) ordination was performed with the $\mathrm{R}$ software, using the vegan package ( $\mathrm{R}$ 165 Development Core Team, 2007). Environmental fitting was performed to evaluate the effects 166 of time as a variable, and phenanthrene as a factor, on the bacterial community. 


\section{DNA extraction and $\mathrm{CsCl}$ gradient fractionation}

169 For SIP200 and SIP2000 experiments, triplicate microcosms were sacrificed at day 5, 10 and 170 14. Soil samples (10 g) were transferred into $50-\mathrm{ml}$ Falcon tubes and stored frozen at $-80^{\circ} \mathrm{C}$ 171 until use. Triplicate $10 \mathrm{-g}$ samples of untreated soil collected at the beginning of the 172 experiment (day 0) served as controls. Duplicate soil samples were also collected at the 173 endpoint (day 14) from control microcosms with no addition. DNA was extracted using the

174 UltraClean Mega Soil DNA kit (MO BIO Laboratories) as recommended. DNA was eluted at $175 \quad 40-50 \mu \mathrm{g} / \mathrm{ml}$ in $8 \mathrm{~mL}$.

176 For $\mathrm{CsCl}$ gradient fractionation, 2-ml portions of the DNA preparations were precipitated, 177 and then adjusted to $700 \mathrm{ng} / \mu \mathrm{l}$ in $\mathrm{H}_{2} \mathrm{O}$. Separation between ${ }^{12} \mathrm{C}$ - and ${ }^{13} \mathrm{C}$-DNA was performed 178 by isopycnic ultracentrifugation on a $\mathrm{CsCl}$ gradient (Luederset al., 2004). Gradients were 179 adjusted to an average density of $1.725 \mathrm{~g} / \mathrm{mL}$ in $3.3 \mathrm{ml} \mathrm{OptiSeal^{ \textrm {TM } }}$ polyallomer centrifuge 180 tubes (Beckman Coulter), and loaded with 30 to 50 micrograms of soil DNA and $5 \mu \mathrm{L}$ of 181 SYBR Safe ${ }^{\mathrm{TM}}$ (Invitrogen) as DNA stain (Martineauet al., 2008). For each run, a tube 182 containing equal amounts of ${ }^{12} \mathrm{C}$-DNA from E. coli and ${ }^{13} \mathrm{C}$-DNA Sphingomonas sp. CHY -1 183 (10 $\mu \mathrm{g}$ each) was processed as a means to control band separation and locate their position in 184 the gradient. ${ }^{13} \mathrm{C}$-labeled genomic DNA was prepared from Sphingomonas sp. CHY-1 grown 185 on ${ }^{13} \mathrm{C}$-succinate (Sigma-Aldrich) as sole carbon source. Preparation of genomic DNA from 186 this strain (Demanecheet al., 2004) and from E. coli strain DH5a (Ausubelet al., 1999) 187 followed published procedures. Ultracentrifugation was carried out at 413,000 x $g_{\text {AV }}$ for $17 \mathrm{~h}$ 188 at $15^{\circ} \mathrm{C}$, in a TLN-100 rotor using an Optima ${ }^{\mathrm{TM}}$ TLX Ultracentrifuge (Beckman Coulter).

189 Gradient fractionation was adapted from a published procedure (Manefieldet al., 2002), using

190 a peristaltic pump operated at a flow rate of $0.18 \mathrm{ml} / \mathrm{min}$ and a Gilson fraction collector 191 equipped with a home-made device for holding centrifuge tubes. Twenty-two fractions, 150 
$192 \mu \mathrm{l}$ each, were obtained, from which DNA was precipitated according to (Pumphrey and

193 Madsen, 2008), using $1 \mu \mathrm{l}$ of $20 \mathrm{mg} / \mathrm{ml}$ glycogen as a carrier (Fermentas). Each fraction was

194 taken up in $20 \mu \mathrm{l} \mathrm{H}_{2} \mathrm{O}$ and DNA concentration was determined from UV absorbance

195 measurement with a ND-100 spectrophotometer (NanoDrop Technologies, Inc.). In plots of

196 DNA content versus fraction number, peak fractions of ${ }^{13} \mathrm{C}$-DNA and unlabeled DNA were 4

197 fractions apart.

198

199 Construction of 16S rRNA gene libraries and DNA sequencing

200 Both the labeled and unlabeled DNA isolated from the SIP200 and SIP2000 experiments, as

201 well as DNA extracted from untreated soil (control SIP 0D), was used as template to amplify

202 the nearly complete sequences of bacterial 16S rRNA genes. PCR amplification was

203 performed with primers 8F (AGAGTTTGATCCTGGCTCAG) and 1390R

204 (GACGGGCGGTGTGTACAA). PCR products were ligated into pCR ${ }^{\mathrm{TM}} 4$ TOPO® ${ }^{\circledR}$ A

205 vectors and electroporated into ElectroMAX ${ }^{\mathrm{TM}} \mathrm{DH} 10 \mathrm{~B}^{\mathrm{TM}} \mathrm{T} 1$ competent cells according to the

206 manufacturer's recommendations (Invitrogen). Bidirectional Sanger sequence reads were

207 obtained by standard procedures and assembled by PHRAP (http://www.phrap.org). Sequence

208 data obtained from clone libraries have been submitted to DDBJ/EMBL/GenBank under

209 accession numbers: FQ658499 to FQ660546 and FQ790244.

210

211 Sequence analysis

212 The 16S rRNA gene sequences were first affiliated to b acterial taxa using SeqMatch on the

213 Ribosomal Database Project (RDP) website (http://rdp.cme.msu.edu/index.jsp ; (Coleet al.,

214 2009)). Multiple sequence alignments and clustering into Operational Taxonomic Units

215 (OTUs) of the 2049 sequences considered herein were performed with mothur (Schlosset al.,

216 2009), using a 3\% dissimilarity level between OTUs. Mothur was also used to generate 
217 rarefaction curves and calculate richness estimators and diversity index (Table 1). A

218 phylogenetic tree was generated using the TreeBuilder software on the RDP website.

\section{Selection of 16S rRNA sequences representative of phenanthrene degraders}

In DNA-SIP analysis, the set of $16 \mathrm{~S}$ RNA sequences recovered from ${ }^{13} \mathrm{C}-\mathrm{DNA}$ may be

contaminated by unspecific sequences due to some overlap between labeled and unlabeled

fractions after isopycnic centrifugation. A control experiment is usually carried out involving

DNA analysis of a sample incubated with unlabeled substrate. After $\mathrm{CsCl}$ gradient separation,

225 a fraction equivalent to that containing ${ }^{13} \mathrm{C}$-DNA in the labeled experiment (heavy fraction), is

226 chosen to run control PCR. In our hands, the choice of the heavy fraction for control purposes

227 was somewhat arbitrary due to small changes in gradient density between samples. In

228 addition, the reliability of this type of control requires that incubation conditions be identical

229 between the SIP and control samples, which is difficult to achieve due to the inherent

230 heterogeneity of soil. Hence, in his study, $16 \mathrm{~S}$ rRNA sequences from ${ }^{13} \mathrm{C}$-DNA libraries were

231 considered representative of phenanthrene degraders if they complied with the following

232 criteria : (i) they had to be part of OTUs represented by a minimum of 3 sequences per library

233 (ii) they were not detected or poorly represented in libraries made from unlabeled DNA from

234 the same run of centrifugation.

236 Real time PCR quantification of phylum-specific 16S rRNA genes

237 The copy number of $16 \mathrm{~S}$ rRNA genes in soil DNA samples was estimated by quantitative

238 PCR (qPCR) using universal or taxon-specific primers according to (Philippotet al., 2010).

239 Amplification reactions were carried out in a StepOnePlus ${ }^{\mathrm{TM}}$ Real-Time PCR Systems

240 (Applied Biosystems). Reaction mixtures contained 7.5 $\mu 1$ SYBRGreen ${ }^{\circledR}$ PCR Master Mix

241 (Absolute QPCR SYBR Green Rox Abgene), 250 ng of T4 gene 32 (QBiogene), 4 ng of soil 
242 DNA in a final volume of $15 \mu$ l. Fluorescence acquisition was performed during $80^{\circ} \mathrm{C}$ steps to 243 avoid interference of unspecific products. For each of the eleven 16S rRNA targets, a standard 244 curve was established using serial dilutions of linearized plasmid pGEM-T $\left(10^{2}\right.$ to $10^{7}$ copies $)$ 245 containing a relevant 16S rRNA gene. Melting curves were generated after amplification by 246 increasing the temperature from $80^{\circ} \mathrm{C}$ to $95^{\circ} \mathrm{C}$. qPCR results are averages of three replicates, 247 and are expressed as copy numbers per nanogram of DNA. The relative abundance of each 248 taxon was calculated as the ratio of copy number of this taxon to the total number of $16 \mathrm{~S}$ 249 rRNA sequences, determined using universal primers. 


\section{Mineralization rates of ${ }^{13} \mathrm{C}$-phenanthrene in microcosms}

254 The soil used in this study had been exposed to chronic hydrocarbon contamination from road 255 runoffs. It contained ca. $4.0 \mathrm{mg} / \mathrm{kg}$ of PAHs, including $0.156 \pm 0.05 \mathrm{mg} / \mathrm{kg}$ of phenanthrene.

256 For SIP experiments, fully labeled ${ }^{13} \mathrm{C}$-phenanthrene was prepared and checked for purity and 257 authenticity by GC-MS and NMR (supplementary Fig. S1). Experiments were carried out in 258 microcosms containing $20 \mathrm{~g}$ of soil, and ${ }^{13} \mathrm{C}$-phenanthrene supplied at 34 and $337 \mathrm{ppm}$, levels 259 equivalent to approx. 200-fold (SIP200) or 2000-fold (SIP2000) the phenanthrene content of 260 soil. Mineralization of the labeled C-source was monitored by GC-MS measurement of the $261{ }^{13} \mathrm{CO}_{2}$ released in the headspace over 14 days (Fig. 1). In SIP2000 experiments, the ${ }^{13} \mathrm{CO}_{2}$ 262 evolution reached a maximum rate after a 2-day lag phase, then leveled off after day 5. No lag 263 phase was observed in microcosms inoculated with Sphingomonas CHY-1, a phenanthrene264 degrading strain, suggesting that the delay reflected the time necessary for multiplication of 265 soil PAH degraders. In SIP200 experiments, the rate of ${ }^{13} \mathrm{CO}_{2}$ was just above the background 266 level detected in control microcosms, which received unlabelled phenanthrene or no addition.

267 From the total amount of ${ }^{13} \mathrm{CO}_{2}$ released in the SIP2000 experiment, it was calculated that ca. $26820 \%$ of the ${ }^{13} \mathrm{C}$-phenanthrene had been mineralized. This value is most likely underestimated 269 as an unknown amount of the carbon dioxide remained trapped in soil as bicarbonate. The 270 residual labeled substrate in soil of the SIP2000 experiment amounted to $20.9 \pm 2.3 \mathrm{ppm}$ at 271 day $5(6.7 \%)$ and $13.9 \pm 1.0 \mathrm{ppm}$ at day $14(4.5 \%)$, meaning that a major part of the added 272 hydrocarbon had been degraded during the early stage of mineralization between days 2 and

273 5. Discrepancy between the mineralization rate and the extent of degradation of ${ }^{13} \mathrm{C}$ 274 phenanthrene (95\%) might be explained in part by underestimations of either ${ }^{13} \mathrm{CO}_{2}$ (see 275 above) or residual phenanthrene due to sequestration into soil particles (Johnsenet al., 2005). 
276 Some of the labeled carbon was also incorporated into the organic matter of phenanthrene

277 degraders.

\section{Effect of phenanthrene on the overall bacterial community structure}

279 To follow changes in the soil bacterial community upon incubation with phenanthrene, soil

280 DNA was extracted at time intervals from SIP and control experiments, and 16S rRNA genes

281 were first analyzed by SSCP fingerprinting. Electrophoresis profiles of PCR products

282 targeting the V3 region were normalized and their distribution was analyzed by non metric

283 multi-dimensional scaling (Fig. 2). Profiles were very similar suggesting that, at this level of

284 observation, the bacterial community underwent little changes with the time of exposition (5,

28510 or 14 d) and the dose of phenanthrene. Nevertheless, a clear trend emerged when

286 comparing data sets at day $0,5,10$ and 14 , in that diversity profiles showed convergent time-

287 dependent variations. On the other hand, diversity profiles obtained from phenanthrene-

288 treated microcosms were more closely related to each other than to untreated controls,

289 suggesting that phenanthrene-dependent shifts occurred in the bacterial population, but these

290 shifts were little correlated to the concentration of phenanthrene.

291 The composition of the bacterial population in soil samples was then analyzed by real-time

292 quantitative PCR (qPCR) using phylum-specific primers (class-specific for Proteobacteria),

293 according to a method that has proven (Philippot, et al., 2010). Samples from the SIP2000

294 experiments showed, small time-dependent variations in 16S rRNA copy numbers (data not

295 shown), suggesting that overall, the community structure was little affected by phenanthrene.

296 However, when abundances were expressed as ratios with respect to the total copy numbers

297 of 16S rRNA genes, a significant increase was found for the Beta- and Gammaproteobacteria

298 (Fig. 3, grey bars). In contrast, Alphaproteobacteria and Actinobacteria showed unchanged or

299 diminished proportions.

300 


\section{Betaproteobacteria enrichment in soil spiked with phenanthrene}

302 Soil bacteria likely involved in phenanthrene degradation were identified based upon 303 sequence analysis of $16 \mathrm{~S}$ rRNA genes amplified from ${ }^{13} \mathrm{C}-\mathrm{DNA}$. Soil DNA samples

304 recovered from SIP200 and SIP2000 experiments at day 5 and day 14 were separated into 305 labeled and unlabeled fractions, both of which were used to prepare 16S rRNA gene libraries

306 (Table 1). Sequences were affiliated to bacterial taxa using the RDP resources.. A detailed 307 compilation of the 2049 sequences analyzed in this study is given in supplementary Table S1.

308 As depicted in Fig. 4, the distribution of sequences among known bacterial phyla revealed 309 that Proteobacteria were predominant in all libraries, the Beta class being the best represented.

310 However, the proportion of Betaproteobacteria sequences was significantly higher in libraries

311 made from labeled DNA, especially SIP2000 at day 5 (67\%). In comparison, the library made

312 out of unlabeled DNA (SIP2000 5D 12C) contained around 30\% of Betaproteobacteria

313 sequences, similar to the library of the untreated control (Fig. 4A and data not show). In the

$314{ }^{13} \mathrm{C}$-DNA extracted from soil dosed with 10 -fold less ${ }^{13} \mathrm{C}$-phenanthrene, a Betaproteobacteria 315 enrichment was also detectable, but only after 14 days (Fig. 4C).

316 Since the PCR-based method used to generate 16S rRNA sequence libraries might introduce

317 biases in the determination of the actual proportions of bacterial taxa in soil, we implemented

318 the quantitative PCR method described above to assess the copy number of taxon-specific16S

319 rRNA genes in ${ }^{13}$ C-DNA fractions. Results illustrated in Fig. 3 showed that labeled DNA was

320 specifically enriched in sequences affiliated to the Betaproteobacteria. The enrichment

321 occurred within the first days of the incubation with ${ }^{13} \mathrm{C}$-phenanthrene, and the proportion of

322 Betaproteobacteria stayed above $10 \%$ throughout the $14-\mathrm{d}$ incubation. Gammaproteobacteria

323 were found to be significantly more abundant at day 10 , suggesting that members of this class

324 also accumulated at least transiently in response to phenanthrene. In comparison, 325 Alphaproteobacteria, and Actinobacteria, as well as other taxa tested (data not shown) were 
326 less represented and their copy number did not show a clear trend upon incubation with

327 phenanthrene. Hence, consistent with the sequence analyses above, our quantitative data

328 demonstrated that Betaproteobacteria became the dominant taxon in response to phenanthrene 329 contamination of soil.

330

\section{Identification of main PAH degraders}

332 Further analysis of sequences in ${ }^{13} \mathrm{C}$-libraries indicated that, at day 5 , the community of PAH 333 degraders exposed to $337 \mathrm{ppm}$ phenanthrene was dominated by a few genera, including 334 Acidovorax, Rhodoferax, Hydrogenophaga and Polaromonas, all members of the

335 Comamonadaceae (Fig. 5A). Quite a few sequences affiliated to Rhodocyclaceae were also 336 identified, but they were not all representative of phenanthrene degraders. Some of them were

337 likely related to degraders as they belonged to OTUs only found in ${ }^{13} \mathrm{C}$-libraries (OTU0, 1 338 and 17), while other were not because they belonged to OTUs mainly found in ${ }^{12} \mathrm{C}$-libraries 339 (OTU28, 51, 71; Fig. 6A). Hence, only some members of the Rhodocyclaceae would be able 340 to degrade phenanthrene. A very similar pattern of dominant taxa was observed in the SIP200 341 experiment at day 14 (Fig. 5B), indicating that a 10-fold lower concentration of phenanthrene

342 elicited the same soil population of degraders, although at a slower pace. Consistent with this 343 idea, comparison of the SIP2000-5D-13C and SIP200-14D-13C libraries showed that they 344 shared the highest number of common OTUs (78 of 161 or 48\%, Fig S2), three of which were 345 dominant in both libraries (OTUs 6, 4 and 17; Fig. 6A).

346 Apart from the Betaproteobacteria, two OTUs related to the Sphingomonadales were 347 significantly represented in sequences obtained from ${ }^{13} \mathrm{C}$-DNA, while almost inexistent in 348 sequences retrieved from unlabeled DNA (OTUs 80 and 201; Fig. 6A). Sphingomonadales 349 accounted for 32 to $37 \%$ of the Alphaproteobacteria sequences in SIP200 ${ }^{13} \mathrm{C}$-libraries, and 350 for 38 to $59 \%$ in SIP2000 ${ }^{13}$ C-libraries, respectively (Fig. S3). One well-represented OTU 
related to unclassified Gammaproteobacteria (OTU 2, 5\% of the SIP2000-5D-13C library)

352 was also detected in the set of sequences obtained from ${ }^{13}$ C-DNA (Fig. 6A).

353 A phylogenetic tree was built with the best represented OTUs found in sequence libraries

354 derived from ${ }^{13} \mathrm{C}-\mathrm{DNA}$ (Fig. 6B). The analysis further highlighted that phenanthrene

355 degraders were dominated by Betaproteobacteria. Except for OTU 4, OTU 6, OTU 12 ,

356 OTU 14 and OTU 27, which were closely related to known isolates, most sequences were

357 either associated to uncultured microorganisms or distantly related to known bacteria. In this

358 respect, OTU 80 and OTU 201, affiliated to Sphingomonadaceae, showed sequences

359 relatively distant from that of known PAH degraders in this bacterial family (Pinyakonget al.,

360 2003; Demaneche, et al., 2004).

361

362 Diversity shifts in the PAH-degrading community as a function of the time of exposure 363 to phenanthrene

364 Comparison of the SIP2000 sequence sets obtained from ${ }^{13} \mathrm{C}-\mathrm{DNA}$ at 5 and 14 days showed 365 that the proportion of Betaproteobacteria dropped from 67 to 35\% (Fig. 4D and E). This 366 change could largely be explained by a decline of the bacterial taxa that were identified as 367 dominant PAH degraders at day 5 (Fig. 5A). At day 14, the best-represented 368 Betaproteobacteria sequences were affiliated to Thiobacillus, a genus that has been seldom 369 described for its ability to degrade aromatic hydrocarbons although it was recognized as a 370 possible phenanthrene degrader (Bodouret al., 2003). A significant proportion of

371 Thiobacillus-like sequences was also detected in the SIP200 sequence sets retrieved from ${ }^{13} \mathrm{C}$ -

372 DNA. Similar to what was observed for the Betaproteobacteria, the OTU 2 related to the

373 Gammaproteobacteria was detected in the SIP2000 library at day 5, but not at day 14 . 
374 On the other hand, Sphingomonads were detectable under all conditions tested, but their

375 number tended to increase in the long run as exemplified by OTU 201, which was undetected

376 at day 5 and represented by 11 sequences (50\% of Alphaproteobacteria) at day 14 (Fig. 6A).

377

\section{DISCUSSION}

379 PAH pollution is persistent in various ecosystems including soils all around the world, and

380 microbial biodegradation is considered the primary process responsible for its natural

381 attenuation. This process has been extensively studied but for a rather limited range of

382 culturable species (Peng, et al., 2008), and little is known on bacterial populations that mainly

383 contribute to PAH removal in situ. In the present study, we have implemented a SIP approach

384 and culture-independent methods to conduct a thorough investigation of phenanthrene

385 degraders present in soil.

386 Overall, the soil community was dominated by Proteobacteria, consistent with previous

387 reports documenting the prevalence of this phylum in different soils (Roeschet al., 2007).

388 Moreover, our results brought convergent pieces of evidence that Betaproteobacteria play a

389 major role in the degradation of phenanthrene in soil. This is supported by the increased

390 proportion of ribosomal sequences representative of this class in ${ }^{13} \mathrm{C}$-DNA in response to

391 phenanthrene, as shown by both qPCR and sequence analysis of cloned 16S rRNA genes.

392 The main PAH degraders identified in this work mostly belong to the Burkholderiales, with

393 Acidovorax, Rhodoferax, Hydrogenophaga and Polaromonas as the best represented genera.

394 Likewise, a SIP study targeting naphthalene degraders, revealed that Polaromonas,

395 Rhodoferax and Acidovorax mainly contribute to in situ degradation (Jeon, et al., 2003),

396 suggesting that the same type of bacteria are responsible for the biodegradation of

397 naphthalene and phenanthrene in soil. Based on 16S rRNA sequence comparison, the

398 dominant Acidovorax identified in this study strikingly resembled members of the same genus 
previously identified in a bioreactor treating a PAH-contaminated soil (Singleton, et al.,

400 2005). A strain isolated from this bioreactor, Acidovorax NA3, has been recently described as

401 a new PAH degrader (Singleton, et al., 2009).

402 Interestingly, most PAH degraders identified in the present study are related to poorly

403 described taxa, consistent with the fact that a majority of soil bacteria are unknown. They

404 differ from PAH-degrading isolates studied so far, and even members of well-known

405 degraders such as Sphingomonadaceae (Demaneche, et al., 2004; Leys, et al., 2004), were

406 found to be distantly related to described strains (Fig. 6). Gammaproteobacteria are

407 represented by one OTU unrelated to known genera of this class, such as Pseudomonas

408 (OTU2; Fig. 6), but very similar to a pyrene-degrading uncultured bacterium detected by SIP

409 in a bioreactor (Singleton, et al., 2006). Moreover, our survey highlighted bacterial taxa

410 affiliated to Rhodocyclaceae and Thiobacillus, which appear as new PAH degraders. Among

411 Rhodocyclaceae, denitrifying bacteria belonging to the Azoarcus, Aromatoleum,

412 Denitratisoma and Thauera genera were shown to anaerobically degrade phenolic

413 compounds (Sueokaet al., 2009) and alkylbenzenes (Rabus and Widdel, 1995; Rotaruet al.,

414 2010), but no Rhodocyclaceae member endowed with PAH-degrading ability has yet been

415 described.

416 Similar populations of degraders were found upon soil treatment with 10-fold different levels

417 of phenanthrene. This observation indicated that, at the highest concentration tested, no

418 adverse effect could be noticed on any of the bacterial taxa involved in phenanthrene

419 degradation. In contrast, different naphthalene degraders were identified in a ground aquifer,

420 depending on the concentration of the hydrocarbon (Huanget al., 2009). In the latter case, the

421 toxic or inhibitory effect of naphthalene might have influenced bacterial selection, in

422 accordance with previous observations (Jeon, et al., 2003). 
423 Time-dependent changes in the population of degraders were observed upon incubation with

424 phenanthrene. The rapid phase of phenanthrene mineralization during the first days coincided 425 with the multiplication in soil of the main degraders discussed above. In the SIP2000 426 experiment, dominant degraders at day 5 drastically declined at day 14. During this time 427 period, the soil bacterial community underwent little change as shown by SSCP and qPCR 428 analyses. Hence, the decline appeared to specifically affect the subpopulation of PAH 429 degraders, maybe because phenanthrene became less bioavailable. Although significant 430 amounts of residual phenanthrene were detected in microcosms after 5 and 14 days, the time 431 course of mineralization suggested that it became limiting at day 5, perhaps due to its 432 sequestration or sorption on soil particles. In the SIP200 experiment, the lower dose of 433 phenanthrene likely elicited slower growth, and might have sustained PAH degraders for a 434 longer time. Hence, our results provide evidence that the subpopulation of degraders undergo 435 relatively rapid dynamic changes in response to the level of PAHs available in soil.

\section{Acknowledgments}

439 We thank N. Duraffourg for assistance in recording RMN spectra, A. Monier and J. Roy for 440 their help in SSCP experiments, E. Pelletier for submitting DNA sequences. F. Martin 441 received a grant from the Rhône-Alpes region. This work was supported by the CNRS and the 442 University of Grenoble.

\section{REFERENCES}

445 Alonso-Gutierrez, J., Figueras, A., Albaiges, J., Jimenez, N., Vinas, M., Solanas, A.M., 446 Novoa, B., 2009. Bacterial communities from shoreline environments (Costa da Morte, 
447 Northwestern Spain) affected by the Prestige oil spill. Appl Environ Microbiol 75, 3407$448 \quad 3418$.

449 Ausubel, F.M., Brent, R., Kingston, R., Moore, D.D., Seidman, J.G., Smith, J.A., Struhl, K., 450 1999. Short protocols in molecular biology. Academic press.

451 Bodour, A.A., Wang, J.-M., Brusseau, M.L., Maier, R.M., 2003. Temporal change in 452 culturable phenanthrene degraders in response to long-term exposure to phenanthrene in a soil 453 column system. Environ Microbiol 5, 888-895.

454 Cebron, A., Louvel, B., Faure, P., France-Lanord, C., Chen, Y., Murrell, J.C., Leyval, C., 455 2011. Root exudates modify bacterial diversity of phenanthrene degraders in PAH-polluted 456 soil but not phenanthrene degradation rates. Environ Microbiol 13, 722-736.

457 Cole, J.R., Konstantinidis, K., Farris, R.J., Tiedje, J.M., 2010. Microbial diversity and 458 phylogeny: extending from rRNAs to genomes, in: Liu, W.T., Jansson, J.K. (Eds.), 459 Environmental Molecular Microbiology. Caister Academic Press, pp. 1-19.

460 Cole, J.R., Wang, Q., Cardenas, E., Fish, J., Chai, B., Farris, R.J., Kulam-Syed-Mohideen, 461 A.S., McGarrell, D.M., Marsh, T., Garrity, G.M., Tiedje, J.M., 2009. The Ribosomal 462 Database Project: improved alignments and new tools for rRNA analysis. Nucleic Acids Res 463 37, D141-D145.

464 Demaneche, S., Meyer, C., Micoud, J., Louwagie, M., Willison, J.C., Jouanneau, Y., 2004. 465 Identification and functional analysis of two aromatic-ring-hydroxylating dioxygenases from 466 a Sphingomonas strain that degrades various polycyclic aromatic hydrocarbons. Appl Environ 467 Microbiol 70, 6714-6725.

468 Doyle, E., Muckian, L., Hickey, A.M., Clipson, N., 2008. Microbial PAH degradation. Adv. 469 Appl. Microbiol. 65, 27-66.

470 Dumont, M.G., Murrell, J.C., 2005. Stable isotope probing - linking microbial identity to 471 function. Nat Rev Microbiol 3, 499-504. 
472 Huang, W.E., Ferguson, A., Singer, A.C., Lawson, K., Thompson, I.P., Kalin, R.M., Larkin, 473 M.J., Bailey, M.J., Whiteley, A.S., 2009. Resolving genetic functions within microbial 474 populations: In situ analyses using rRNA and mRNA stable isotope probing coupled with 475 single-cell Raman-fluorescence in situ hybridization. Appl Environ Microbiol 75, 234-241.

476 Jeon, C.O., Park, W., Padmanabhan, P., DeRito, C.J., Snape, R., Madsen, E.L., 2003.

477 Discovery of a bacterium, with distinctive dioxygenase, that is responsible for in situ 478 biodegradation in contaminated sediment. Proc Natl Acad Sci USA 100 13591-13596.

479 Johnsen, A.R., Wick, L.Y., Harms, H., 2005. Principles of microbial PAH-degradation in soil. 480 Environ. Pollut. 133, 71-84.

481 Jones, M.D., Singleton, D.R., Sun, W., Aitken, M.D., 2011. Multiple DNA extractions 482 coupled with stable-isotope probing of anthracene-degrading bacteria in contaminated soil. 483 Appl. Environ. Microbiol. 77, 2984-2991.

484 Krivobok, S., Kuony, S., Meyer, C., Louwagie, M., Willison, J.C., Jouanneau, Y., 2003. 485 Identification of pyrene-induced proteins in Mycobacterium sp. strain 6PY1: evidence for two 486 ring-hydroxylating dioxygenases. J Bacteriol 185, 3828-3841.

487 Leys, N.M., Ryngaert, A., Bastiaens, L., Wattiau, P., Top, E.M., Verstraete, W., Springael, 488 D., 2005. Occurrence and community composition of fast-growing Mycobacterium in soils 489 contaminated with polycyclic aromatic hydrocarbons. FEMS Microbiol Ecol 51, 375-388.

490 Leys, N.M.E.J., Ryngaert, A., Bastiaens, L., Verstraete, W., Top, E.M., Springael, D., 2004. 491 Occurrence and phylogenetic diversity of Sphingomonas strains in soils contaminated with 492 polycyclic aromatic hydrocarbons. Appl Environ Microbiol 70, 1944-1955.

493 Lueders, T., Manefield, M., Friedrich, M.W., 2004. Enhanced sensitivity of DNA- and rRNA494 based stable isotope probing by fractionation and quantitative analysis of isopycnic 495 centrifugation gradients. Environ Microbiol 6, 73-78. 
Manefield, M., Whiteley, A.S., Griffiths, R.I., Bailey, M.J., 2002. RNA stable isotope

497 probing, a novel means of linking microbial community function to Phylogeny. Appl Environ

498 Microbiol 68, 5367-5373.

499 Martineau, C., Whyte, L.G., Greer, C.W., 2008. Development of a SYBR safe (TM)

500 technique for the sensitive detection of DNA in cesium chloride density gradients for stable

501 isotope probing assays. J Microbiol Methods 73, 199-202.

502 Peng, R.H., Xiong, A.S., Xue, Y., Fu, X.Y., Gao, F., Zhao, W., Tian, Y.S., Yao, Q.H., 2008.

503 Microbial biodegradation of polyaromatic hydrocarbons. FEMS Microbiol Rev 32, 927-955.

504 Philippot, L., Tscherko, D., Bru, D., Kandeler, E., 2010. Distribution of high bacterial taxa

505 across the chronosequence of two alpine glacier forelands. Microb Ecol 61, 303-312.

506 Pinyakong, O., Habe, H., Omori, T., 2003. The unique aromatic catabolic genes in

507 sphingomonads degrading polycyclic aromatic hydrocarbons (PAHs). J Gen Appl Microbiol

$508 \quad 49,1-19$.

509 Pumphrey, G.M., Madsen, E.L., 2008. Field-based stable isotope probing reveals the

510 identities of benzoic acid-metabolizing microorganisms and their in situ growth in agricultural

511 soil. Appl Environ Microbiol 74, 4111-4118.

512 Rabus, R., Widdel, F., 1995. Anaerobic degradation of ethylbenzene and other aromatic-

513 hydrocarbons by new denitrifying bacteria. Arch Microbiol 163, 96-103.

514 Radajewski, S., Ineson, P., Parekh, N.R., Murrell, J.C., 2000. Stable-isotope probing as a tool

515 in microbial ecology. Nature 403, 646-649.

516 Roesch, L.F.W., Fulthorpe, R.R., Riva, A., Casella, G., Hadwin, A.K.M., Kent, A.D., Daroub,

517 S.H., Camargo, F.A.O., Farmerie, W.G., Triplett, E.W., 2007. Pyrosequencing enumerates

518 and contrasts soil microbial diversity. ISME J 1, 283-290.

519 Rotaru, A.-E., Probian, C., Wilkes, H., Harder, J., 2010. Highly enriched Betaproteobacteria

520 growing anaerobically with p-xylene and nitrate. FEMS Microbiol Ecol 71, 460-468. 
521 Schloss, P.D., Westcott, S.L., Ryabin, T., Hall, J.R., Hartmann, M., Hollister, E.B.,

522 Lesniewski, R.A., Oakley, B.B., Parks, D.H., Robinson, C.J., Sahl, J.W., Stres, B., Thallinger,

523 G.G., Van Horn, D.J., Weber, C.F., 2009. Introducing mothur: open-source, platform524 independent, community-supported software for describing and comparing microbial 525 communities. Appl. Environ. Microbiol. 75, 7537-7541.

526 Singleton, D.R., Powell, S.N., Sangaiah, R., Gold, A., Ball, L.M., Aitken, M.D., 2005. Stable-

527 isotope probing of bacteria capable of degrading salicylate, naphthalene, or phenanthrene in a 528 bioreactor treating contaminated soil. Appl Environ Microbiol 71, 1202-1209.

529 Singleton, D.R., Ramirez, L.G., Aitken, M.D., 2009. Characterization of a polycyclic 530 aromatic hydrocarbon degradation gene cluster in a phenanthrene-degrading Acidovorax 531 strain. Appl Environ Microbiol 75, 2613-2620.

532 Singleton, D.R., Sangaiah, R., Gold, A., Ball, L.M., Aitken, M.D., 2006. Identification and 533 quantification of uncultivated proteobacteria associated with pyrene degradation in a 534 bioreactor treating PAH-contaminated soil. Environ Microbiol 8, 1736-1745.

535 Sueoka, K., Satoh, H., Onuki, M., Mino, T., 2009. Microorganisms involved in anaerobic 536 phenol degradation in the treatment of synthetic coke-oven wastewater detected by RNA 537 stable-isotope probing. FEMS Microbiol Lett 291, 169-174.

538 Wackett, L.P., 2004. Stable isotope probing in biodegradation research. Trends biotechnol. $53922,153-154$.

540 Willison, J.C., 2004. Isolation and characterization of a novel sphingomonad capable of 541 growth with chrysene as sole carbon and energy source. FEMS Microbiol Lett 241, 143-150.

542 Zinger, L., Gury, J., Giraud, F., Krivobok, S., Gielly, L., Taberlet, P., Geremia, R.A., 2007. 543 Improvements of polymerase chain reaction and capillary electrophoresis single-strand 544 conformation polymorphism methods in microbial ecology: Toward a high-throughput 545 method for microbial diversity studies in soil. Microb Ecol 54, 203-216. 
Table 1 : Description of the nine 16S rRNA sequence libraries considered in the DNA SIP experiments.

547

\begin{tabular}{lcccccc}
\hline Library & Sequence & OTU & \multicolumn{2}{c}{ Richness estimation } & & Diversity Index \\
& number & number & Chao1 & Ace & Shannon \\
\hline SIP1 0D & 230 & 173 & 468 & 892 & 4.87 \\
SIP200 5D 13C & 167 & 132 & 810 & 783 & 4.67 \\
SIP200 5D 12C & 147 & 135 & 938 & 1897 & 4.82 \\
SIP200 14D 13C & 353 & 161 & 748 & 2144 & 4.32 \\
SIP200 14D 12C & 259 & 233 & 572 & 956 & 4.96 \\
SIP2000 5D 13C & 423 & 173 & 536 & 942 & 3.89 \\
SIP2000 5D 12C & 228 & 186 & 739 & 1981 & 5.01 \\
SIP2000 14D 13C & 212 & 135 & 476 & 877 & 3.20 \\
SIP2000 14D 12C & 28 & 27 & 118 & 182 & 3.23 \\
\hline
\end{tabular}


550 Figure 1: Time course of ${ }^{13} \mathrm{CO}_{2}$ evolution during SIP experiments as measured by GC/MS.

$551{ }^{13} \mathrm{CO}_{2}$ was measured in the headspace of microcosms supplied with either $34 \mathrm{ppm}(\triangle$;

552 SIP200) or 337 ppm ( $\mathbf{\Delta}$; SIP2000) ${ }^{13}$ C-phenanthrene, at the beginning of the incubation. Two

553 microcosms spiked with 337 ppm ${ }^{13} \mathrm{C}$-phenanthrene were inoculated with Sphingomonas

554 CHY-1 $(\diamond)$. Other experimental conditions included addition of $34 \mathrm{ppm}$ unlabelled

555 phenanthrene $(\square)$, no addition $(\square)$ and abiotic control $(\mathrm{O})$. Data show net ${ }^{13} \mathrm{CO}_{2}$ evolution

556 calculated by subtracting natural ${ }^{13} \mathrm{CO}_{2}$ present in the air. Data are averages of three replicate

557 treatments for SIP200 and SIP2000, and two replicates for other experimental conditions.

558 Error bars indicate standard deviations.

560 Figure 2: NMDS ordination of bacterial communities exposed to phenanthrene, based on

561 SSCP fingerprint analysis.

562 SSCP profiles were computed and compared through nonmetric multidimensional scaling

563 using a stress value of 9.46. Data fitting was applied to examine the effects of phenanthrene

564 and incubation time on the ordination. Phenanthrene concentration was $34 \mathrm{ppm}(\mathbf{\square}), 337 \mathrm{ppm}$

565 ( $\mathbf{\Delta})$ or background level $(\bullet)$. Incubation time (days) was 0 (orange symbols), 5 (red), 10

566 (blue), or 14 (green). Vector indicates time variable $(P<0.001)$, centroides denote

567 phenanthrene level added: none (PheNo), 34 ppm (PheLw) or 337 ppm (PheHg) $(P<0.002)$.

569 Figure 3: Relative abundances of phylum-specific 16S rRNA genes in soil DNA during

570 incubation with ${ }^{13} \mathrm{C}$-phenanthrene. Template was either total soil DNA (grey bars) or ${ }^{13} \mathrm{C}$ -

571 DNA (black bars) extracted from SIP2000 experiments at 5, 10 and 14 days (5D, 10D and

572 14D, respectively). A control DNA sample was obtained from soil incubated for 14 days 
573 without phenanthrene (T14D). Stars denote significant differences compared to control DNA

574 from non-incubated untreatz)ed soil (0D;P<0.05). A: Alphaproteobacteria; B:

575 Betaproteobacteria; C: Gammaproteobacteria; D: Actinobacteria.

576

577 Figure 4: Prevalence of Betaproteobacteria-specific sequences in 16S rRNA gene libraries

578 recovered from ${ }^{13} \mathrm{C}$-labeled soil DNA.

579 Chart pies represent sequence repartition into main taxa for the following 16S rRNA gene

580 libraries: A, SIP1 0D (control); B, SIP200 5D 13C; C, SIP200 14D 13C; D, SIP2000 5D 13C;

581 E, SIP2000 14D 13C. Other phyla include Bacteroidetes, Chloroflexi, Spirochete,

582 Verrucomicrobia, Cyanobacteria, Gemmatimonadetes, Firmicutes, Planctomycete and 583 Nirospira.

584

585 Figure 5 : Distribution of Betaproteobacteria into best-represented families and genera.

586 Sequences were from ${ }^{13}$ C-DNA libraries prepared at day 5 and 14 from the SIP2000 (A) and

587 the SIP200 (B) experiments, or from a control DNA library made from untreated soil (SIP

588 0D). Ratios were calculated as the number of sequences per taxon versus the total number of

589 sequences affiliated to Betaproteobacteria in each library.

590

591 Figure 6: Major bacterial taxa likely involved in ${ }^{13} \mathrm{C}$-phenanthrene degradation.

592 From a compilation of all 2049 16S rRNA gene sequences considered herein, grouping in

593 OTUs was performed with mothur. A : Diagram showing the sequence number of those

594 OTUs exclusively or mainly consisting of sequences derived from ${ }^{13} \mathrm{C}$-DNA. B : Phylogenetic

595 tree illustrating the relationships between these OTUs and most similar sequences found in

596 the RDP data-base. Affiliation to relevant bacterial taxa is indicated on the left. The tree was 
597 built with TreeBuilder found on the RDP website, using the Aquifex pyrophilus 16S rRNA 598 gene as an outgroup sequence. 


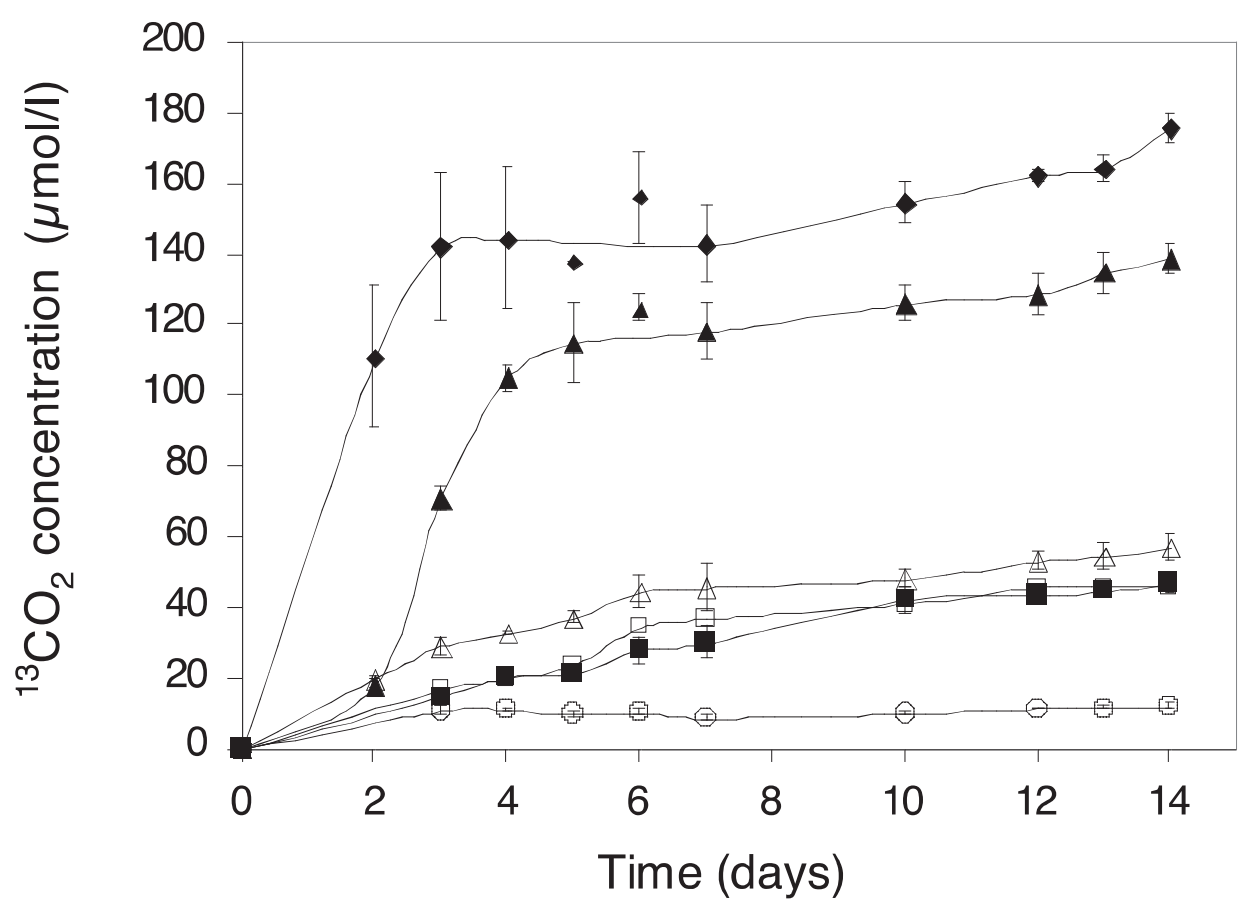

Figure 1: Time course of ${ }^{13} \mathrm{CO}_{2}$ evolution during SIP experiments as measured by GC/MS. ${ }^{13} \mathrm{CO}_{2}$ was measured in the headspace of microcosms supplied with either $34 \mathrm{ppm}(\triangle$; SIP200) or $337 \mathrm{ppm}\left(\mathbf{\Delta}\right.$; SIP2000) ${ }^{13} \mathrm{C}$-phenanthrene, at the beginning of the incubation. Two microcosms spiked with 337 ppm ${ }^{13} \mathrm{C}$-phenanthrene were inoculated with Sphingomonas CHY-1 $(\diamond)$. Other experimental conditions included addition of $34 \mathrm{ppm}$ unlabelled phenanthrene $(\square)$, no addition $(\square)$ and abiotic control $(\mathrm{O})$. Data show net ${ }^{13} \mathrm{CO}_{2}$ evolution calculated by subtracting natural ${ }^{13} \mathrm{CO}_{2}$ present in the air. Data are averages of three replicate treatments for SIP200 and SIP2000, and two replicates for other experimental conditions. Error bars indicate standard deviations. 


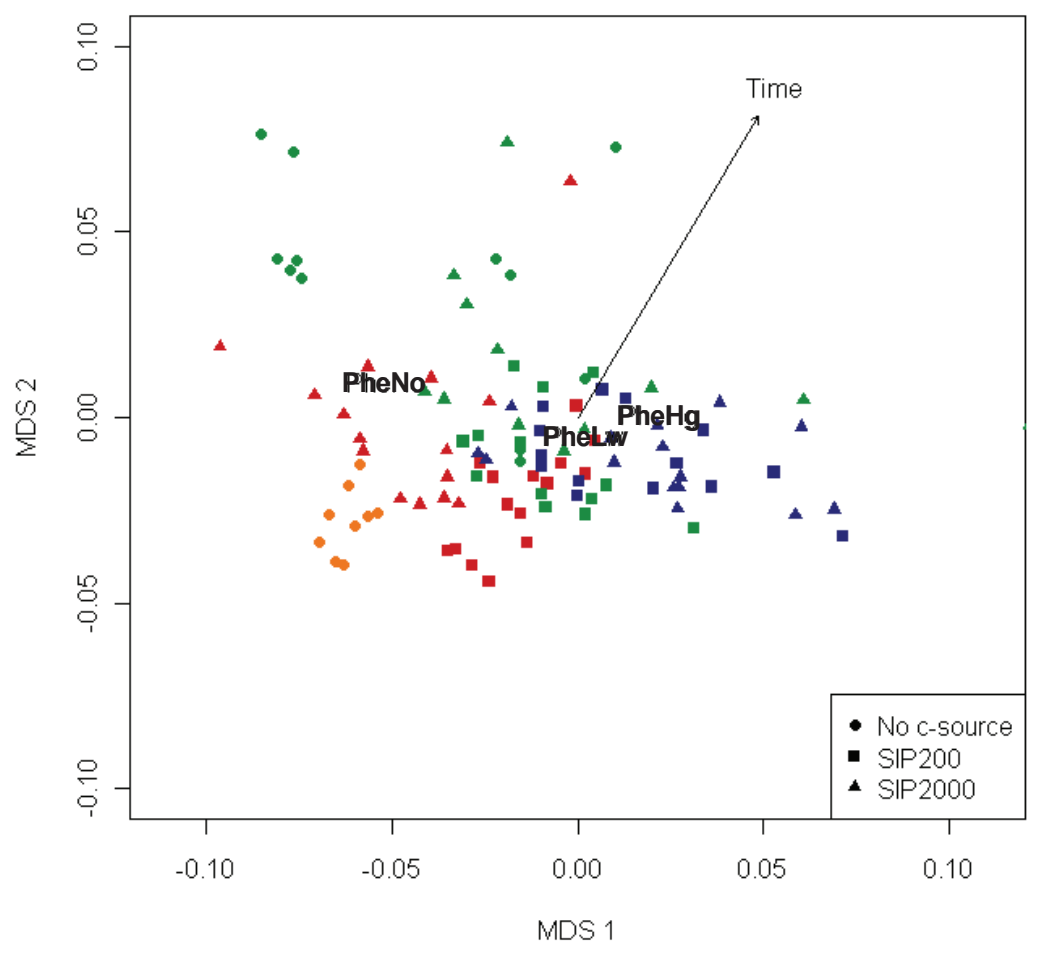

Figure 2: NMDS ordination of bacterial communities exposed to phenanthrene, based on SSCP fingerprint analysis.

SSCP profiles were computed and compared through non metric multidimensional scaling using a stress value of 9.46. Data fitting was applied to examine the effects of phenanthrene and incubation time on the ordination. Phenanthrene concentration was $31 \mathrm{ppm}(\mathbf{\square}), 310 \mathrm{ppm}$ $(\boldsymbol{\Delta})$ or background level $(\bullet)$. Incubation time (days) was 0 (orange symbols), 5 (red), 10 (blue), or 14 (green). Vector indicates Time variable $(\mathrm{P}<0.001)$, centroides denote phenanthrene level added: none (PheNo), 31 ppm (PheLw) or 310 ppm (PheHg) $(\mathrm{P}<0.002)$. 

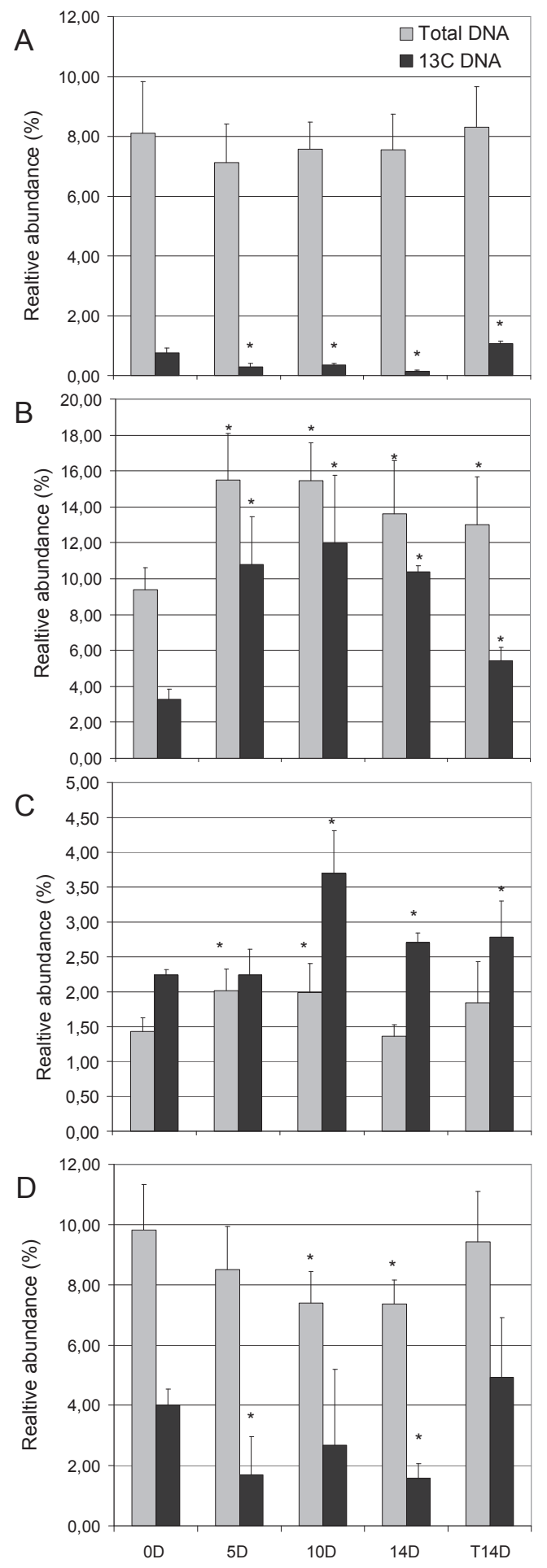

Figure 3: Relative abundances of phylum-specific 16S rRNA genes in soil DNA during incubation with ${ }^{13} \mathrm{C}$-phenanthrene. Template was either total soil DNA (grey bars) or ${ }^{13} \mathrm{C}$ DNA (black bars) extracted from SIP2000 experiments at 5, 10 and 14 days (5D, 10D and 14D, respectively). A control DNA sample was obtained from soil incubated for 14 days 
without phenanthrene (T14D). Stars denote significant differences compared to control DNA from non-incubated soil (0D; $p<0.05)$. A: Alphaproteobacteria; B: Betaproteobacteria; C: Gammaproteobacteria; D: Actinobacteria. 

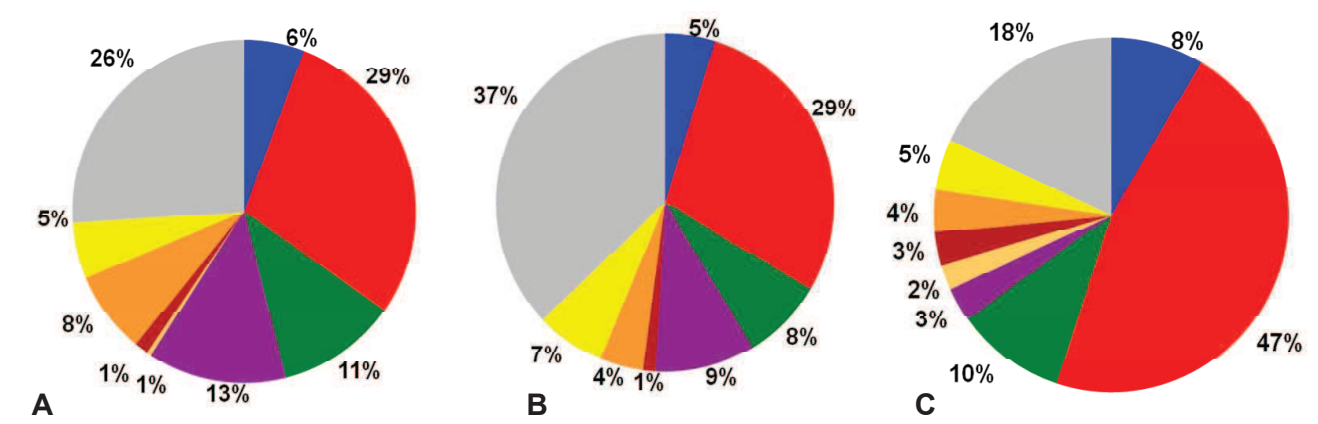

$\square$ Alpha proteobacteria

口Beta proteobacteria

-Gamma proteobacteria

-Delta proteobacteria

口Epsilon proteobacteria

-Actinobacteria

$\square$ Acidobacteria
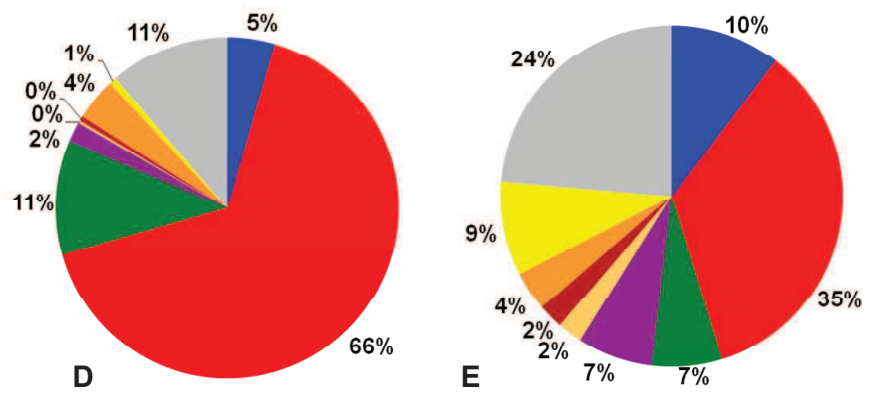

口Unclassified bacteria

口Other phyla

Figure 4: Prevalence of Betaproteobacteria-specific sequences in 16S rRNA gene libraries recovered from ${ }^{13} \mathrm{C}$-labeled soil DNA.

Chart pies represent sequence repartition into main taxa for the following 16S rRNA gene libraries: A, SIP1 0D (control); B, SIP200 5D 13C; C, SIP200 14D 13C; D, SIP2000 5D 13C; E, SIP2000 14D 13C. "Other phyla" include Bacteroidetes, Chloroflexi, Spirochete, Verrucomicrobia, Cyanobacteria, Gemmatimonadetes, Firmicutes, Planctomycete and Nirospira. 

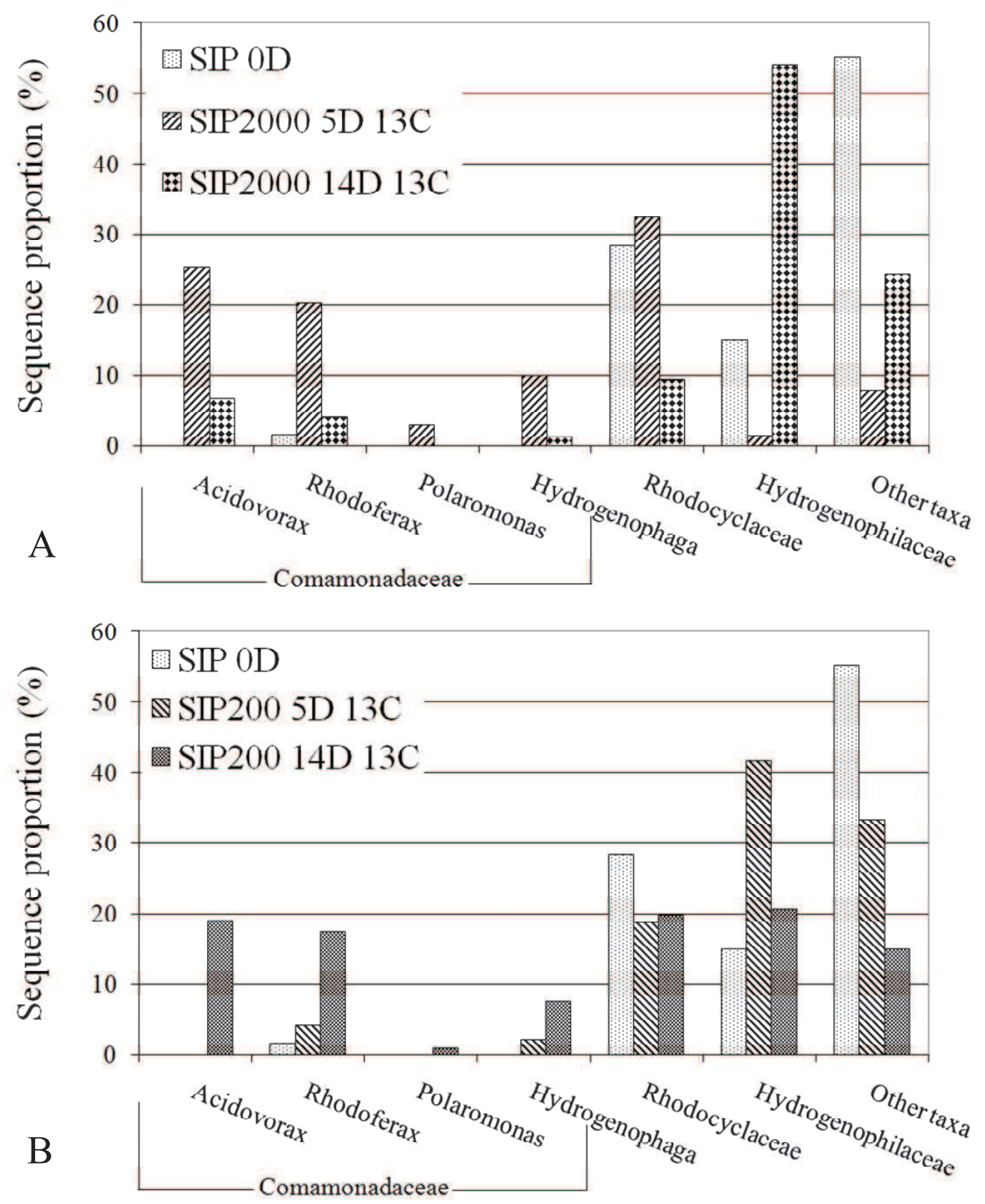

Figure 5: Distribution of Betaproteobacteria into best-represented families and genera.

Sequences were from ${ }^{13}$ C-DNA libraries of the SIP2000 (A) and the SIP200 (B) experiments, or from the untreated soil DNA library (SIP 0D). Ratios were calculated as the number of sequences per taxon versus the total number of sequences affiliated to Betaproteobacteria in each library. 
Figure

Click here to download Figure: Figure 6.pdf
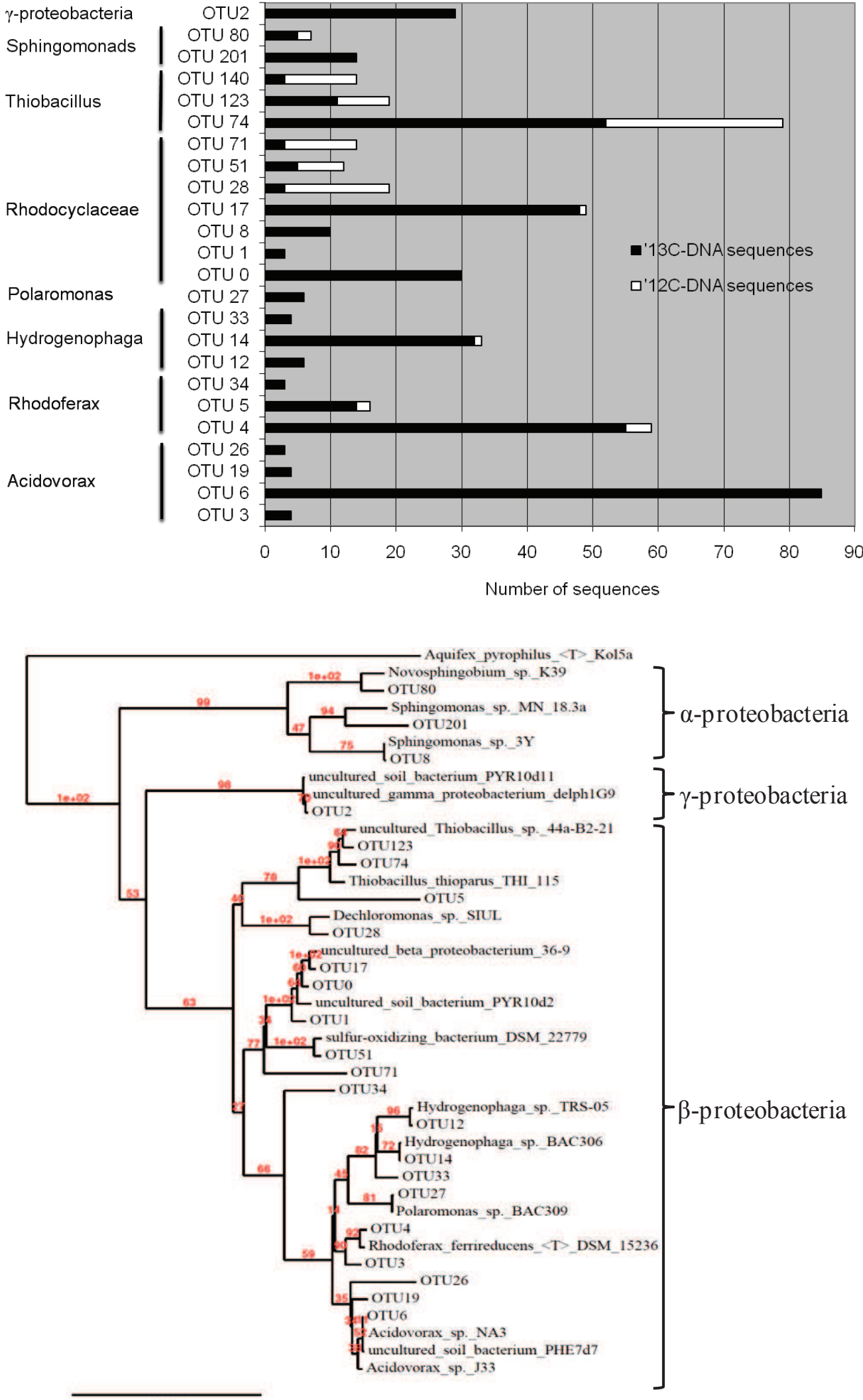

0.08

B

Figure 6 
Figure 6 : Major bacterial taxa likely involved in ${ }^{13} \mathrm{C}$-phenanthrene degradation.

From a compilation of all 2049 16S rRNA gene sequences considered herein, grouping in OTUs was performed with mothur. A : Diagram showing the sequence number of those OTUs exclusively or mainly consisting of sequences derived from ${ }^{13} \mathrm{C}$-DNA. B : Phylogenetic tree illustrating the relationships between these OTUs and most similar sequences found in the RDP data-base. Affiliation to relevant bacterial taxa is indicated on the left. The tree was built with TreeBuilder found on the RDP website, using the Aquifex pyrophilus 16S rRNA gene as an outgroup sequence.

Figure 6 
Supplementary Files
Click here to download Supplementary Files: Table S1.xls s

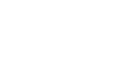
(1)

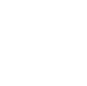
(1) (1) (n) (n) (1)

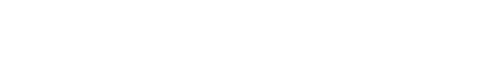

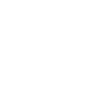
(1) (1)

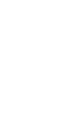

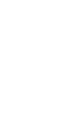

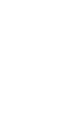

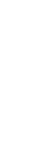
(n)

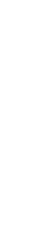
. n

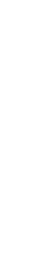

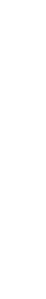

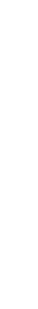
n . . 列 (1) . (1)

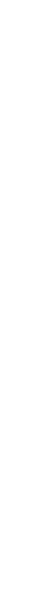
列 . 
Click here to download Supplementary Files: Figures S1-S3.pdf 